\title{
ОЦЕНКА УСТОЙЧИВОСТИ ЭКОНОМИЧЕСКИХ СИСТЕМ, ОПИСЫВАЕМЫХ ЭКОНОМИЧЕСКИМИ ЦЕНОЗАМИ, НА ПРИМЕРЕ БАНКОВСКОГО СЕКТОРА РЕСПУБЛИКИ МОЛДОВА
}

\author{
(c) 2019 Ступачев Сергей Александрович \\ докторант \\ Академия экономического образования Республики Молдова, Кишинев \\ E-mail: stypachev@mail.ru
}

На основании проведенного с 2014 по 2018 гг. ценологического анализа банковского сектора экономики Республики Молдова рассчитаны оценки его финансово-экономической устойчивости и получены ранговые параметрические распределения банковских организаций. Значения показателей устойчивости позволяют оценить влияние внешних факторов (мировых экономических кризисов, инвестиций Международных Финансовых Организаций) на устойчивость банковского сектора Молдовы. Структура ранговых параметрических распределений позволяют определить наиболее проблемные места банковского сектора, и на основании этого сформулировать рекомендации по реализации повышения его устойчивости.

Ключевые слова: Международные финансовые организации, экономическая система, банковский сектор, экономический ценоз, ранговое параметрическое распределение, гиперболическое Н-распределение.

Республика Молдова после распада СССР находится в процессе интеграции в систему мировых финансово-экономических связей. Для интенсификации этого трансформационного процесса и своего экономического развития она в основном использует финансовые ресурсы ведущих Международных Финансовых Организаций (МФО), (таких как: (группа Всемирного Банка, Международный Валютный Фонд и др.) Как показывает практики, во время мировых кризисных явлений, в первую очередь страны с развивающейся рыночной экономикой, к которым относится и Молдова, оказываются в очень сложной финансово-экономической ситуации. Вследствие этого для решения возникших неотложных финансово-экономических проблем и для проведения эффективной финансово-экономической политики возникает необходимость сотрудничества Республики Молдова с этими финансовыми организациями. Эффективность использования выделяемых финансовых ресурсов МФО определяется повышением экономической устойчивости страны. Поэтому задача оценки устойчивости экономической системы Республики Молдовы в рамках сотрудничества с МФО в процессе интеграции ее экономики в систему мировых финансово-экономических связей является актуальной.

Оценка устойчивости и изменения эконо- мической структуры страны осуществляется на основе понятия экономического ценоза - модели экономической системы в рамках концепции эволюционной экономики и эволюционной теории экономических изменений [3]. Анализ структурных изменений экономики на основе ценологической теории, в которой экономическая система рассматривается как экономический ценоз позволяет осуществить оценку ее устойчивости и определить проблемные места в ее структуре $[1,5]$.

Экономический ценоз определяется как «самоорганизующееся многовидовое сообщество организаций различных отраслей выделенного территориально-административного образования, характеризующееся связями различной силы (сильными, средними и преимущественно слабыми), объединенное совместным использованием природных, технологических, социальных ресурсов и экономических ниш спроса на продукцию, товары и услуги, с действием внутривидового и межвидового отбора» [5].

В качестве территориально-административного образования рассматривается Республика Молдова, а в качестве экономического ценоза анализируется ее банковский сектор, который является одним из основных в экономической системе страны.

В процессе ценологического анализа бан- 
ковского сектора используются его ранговые параметрические распределения [4], построенные на основе информативно доступных ключевых значений годовых финансово-экономических показателей банковских организаций Республики Молдова. Формирование рангового параметрического распределения осуществляется путем нумерации (ранжирования) всех банков в соответствии убывания величины выбранного финансово-экономического показателя. Соответственно первый ранг соответствует банку с наибольшим показателем. Параметры и структуры, построенных за некоторое время наблюдения ранговых параметрических распределений выделенного экономического ценоза (банковского сектора) дают возможность определить его структурное изменение и оценку его устойчивости [5].

Согласно ценологической теории оценка устойчивости рассматриваемого банковского сектора Молдовы определяется в процессе сравнения построенного для каждого выбранного банковского финансового показателя рангового параметрического распределения и аппроксимирующей его функции в виде классического гиперболического Н-распределения [2]:

$$
\mathrm{P}(\mathrm{r})=\mathrm{P}_{1} / \mathrm{r}^{\beta}
$$

где:

$\mathrm{P}(\mathrm{r})$ - значение банковского финансового показателя с рангом r;

$\mathrm{P}_{1}$ - постоянная величина равная максимальному значению этого показателя (банковская организация с рангом 1);

$\beta$ - ранговый коэффициент, определяющий степень крутизны гиперболы Н распределения.

Из формулы (1) следует, что параметры $\mathrm{P}_{1}$ и $\beta$ однозначно определяют функцию Н распределения, при этом $\mathrm{P}_{1}$ определяет начальную точку, а параметр $\beta$ крутизну гиперболического $\mathrm{H}$ распределения.

Как показывает многолетняя практика статистических наблюдений ранговые параметрические распределения экономических ценозов в процессе их самоорганизации и эволюции в условиях приближенных к свободной рыночной конкуренции стремятся к гиперболическому Н-распределению с ранговым коэффициентом в интервале $\beta \in[0,5 ; 1,5]$ [2]. Такие ранговые параметрические распределения экономических ценозов являются наиболее устойчивыми по срав- нению с другими, и считаются оптимальными.

Параметры $\mathrm{P}_{1}$ и $\beta$ аппроксимирующей функции гиперболического Н-распределения (1) эмпирических данных рангового параметрического распределения определяются на основе процедур метода наименьших квадратов из условия:

$$
\min \sum_{r=1}^{N}\left[P_{f}(r)-P_{1} / r^{\beta}\right]^{2}
$$

где $\mathrm{P}_{\mathrm{f}}$ есть ранговое параметрическое распределение, построенное на фактических (эмпирических) данных за финансовый год ключевых финансово-экономических показателей банков Молдовы.

Оценку устойчивости экономического ценоза - его близости к оптимальной структуре Н-распределения, предлагается определять с помощью безразмерного показателя устойчивости:

$$
\Pi=\sum_{\mathrm{r}=1}^{\mathrm{N}}\left[\mathrm{P}_{\mathrm{f}}(\mathrm{r})-\mathrm{P}_{1}^{*} / \mathrm{r}^{\beta^{*}}\right]^{2} /\left(\sum_{\mathrm{r}=1}^{\mathrm{N}} \mathrm{P}_{\mathrm{f}}(\mathrm{r})\right)^{2}
$$

где $\mathrm{P}_{1}^{*}$ и $\beta^{*}$ есть решение задачи (2), a $\mathrm{P}_{1}^{*} / \mathrm{r} \beta^{*}$ является гиперболическим Н-распределением с ранговым коэффициентом в интервале $\beta * \in[0,5 ; 1,5]$.

Данный показатель может служить индикатором устойчивости экономического ценоза (банковского сектора), чем он меньше, тем ближе структура ценоза банковского сектора к оптимальной. При этом анализ изменения этого показателя за временной период действия международной финансовой помощи Республике Молдова дает возможность оценить ее эффективность и влияния на банковский сектор в целом.

На основе представленной методики оценки устойчивости экономических систем производится анализ устойчивости банковского сектора экономики Республики Молдова с 2014 г. по 2018г включительно. Для каждого года этого временного периода и ключевого показателя деятельности организаций банковского сектора экономики Республики Молдова - процентного дохода за год [6], выраженного в молдавских леях, осуществляется построение ранговых параметрических распределений.

Анализ изменения рангов, полученных ран- 
говых распределений процентного дохода банковского сектора показывает, что за время с 2014 г. по 2018 г. в структуре банковского ценоза произошли существенные изменения - все банки Молдовы, за исключением двух первых по рангу (BC «MOLDOVA-AGROINDBANK» S.A. и BC «Moldindconbank» S.A.), меняли свои ранги. Обычно такие изменения ранговых параметрических распределений экономической системы связаны с процессами формирования экономических ценозов под существенным воздействием постоянно меняющихся финансово-экономических условий, как внешних, так и внутренних.

Графическая иллюстрация рангового параметрического распределения, построенного на основании данных годового отчета банков Молдовы за 2018 г. [6], и ее аппроксимации гиперболическим Н-распределением представлена графиком на рис. 1. Параметры $\mathrm{P}_{1}$ и $\beta$, полученные в результате решения (2) единственным образом определяют аналитический вид гиперболического Н-распределения.
Численное решение оптимизационной задачи (2) осуществляется в программной среде Matlab с помощью функции «fminsearch». Микрофинансовые организации Молдовы не рассматриваются в процессе ценологического анализа по причине отсутствия точной информации их финансово-экономической деятельности. Однако такой подход никоим образом не влияет на корректность произведенного анализа и осуществленные расчеты в виду малости их финансово-экономических показателей, которыми по отношению к соответствующим показателям рассматриваемых лицензионных банков можно пренебречь.

Параметры $\mathrm{P}_{1}$ и $\beta$, аппроксимирующих кривых гиперболического Н-распределения для ранговых параметрических распределений процентного дохода банков с 2014 по 2018 г., полученные в процессе решения оптимизационной задачи (2), а также показатели устойчивости структуры банковского сектора страны, вычисленные по формуле (3), представлены в таблице 1.

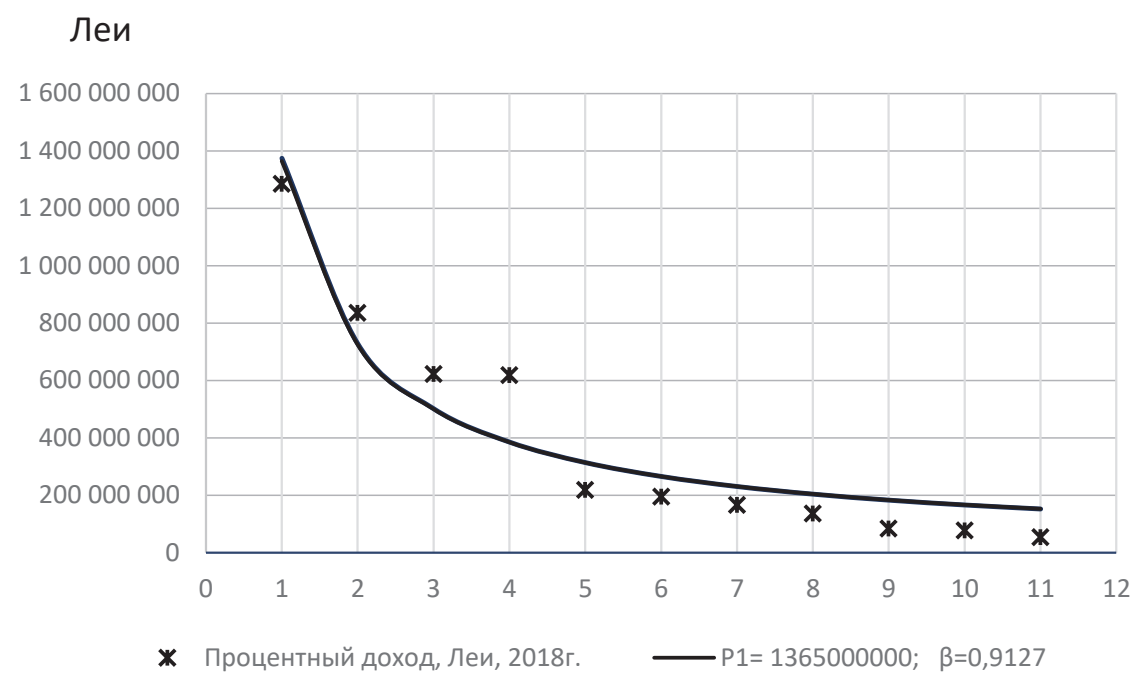

Puc. 1. Аппроксимирующая кривая гиперболического Н-распределения рангового параметрического распределения процентного дохода банков Молдовы за 2018 г.

Таблица 1. Параметры $\mathbf{P}_{1}$ и $\beta$, аппроксимирующих кривых гиперболического Н-распределения для ранговых параметрических распределений процентного дохода банков. Показатели устойчивости - П

\begin{tabular}{|c|c|c|c|c|c|}
\hline $\begin{array}{c}\text { Параметры Р и } \beta . \\
\text { Показатель устойчи- } \\
\text { вости - П }\end{array}$ & $\mathbf{2 0 1 4}$ г. & $\mathbf{2 0 1 5}$ г. & $\mathbf{2 0 1 6}$ г. & $\mathbf{2 0 1 7}$ г. & $\mathbf{2 0 1 8}$ г. \\
\hline $\mathrm{P}_{1}$ & 1234600000 & 1673900000 & 1850900000 & 1463600000 & 1365000000 \\
\hline$\beta$ & 0,6941 & 0,8643 & 0,8385 & 0,8851 & 0,9127 \\
\hline$\Pi$ & 0,00774 & 0,01384 & 0,01475 & 0,00860 & 0,00748 \\
\hline
\end{tabular}


Анализ данных таблицы 1 показывает, что все аппроксимирующие кривые Н-распределений для ранговых параметрических распределений процентного дохода банков Молдовы являются оптимальными, т.е. их ранговые коэффициенты находятся в интервале $\beta \in[0,5 ; 1,5]$. Это показывает, что банковский сектор Республики Молдова по отношению к процентному доходу с 2014 г. по 2018 г. обладал финансовой устойчивостью. Степень оптимальной устойчивости банковского сектора определяется значением показателя устойчивости, чем меньше его величина, тем устойчивее в финансовом смысле рассматриваемый банковский сектор Молдовы.

Сравнение рангового параметрического распределения процентного дохода банков за 2018 г. и его аппроксимирующей гиперболы Н-распределения на рисунке 1 показывает, что улучшения структуры банковского сектора страны (уменьшение показателей устойчивости) возможно, например, за счет изменения процентных доходов первых четырех банков с рангами 1, 2, 3 и 4 (увеличения процентных доходов банков с рангами 1,2 , и оптимизация процентных доходов банков с рангами 3, 4). Улучшение структуры банковского сектора целесообразно осуществлять с помощью соответствующих финансовых ресурсов МФО, направляя их на улучшение общей финансово-экономической ситуации в стране и создания конкурентной среды в банковской сфере, что ускорит формирования эффективного банковского сектора, его развития и финансово-экономической стабильности.
На рисунке 2 представлен график динамики показателя устойчивости П с 2014 по 2018 г., построенный на основании данных таблицы 2.

Из графика на рисунке 2 видно, что свои минимальные значения показатель устойчивости достигал в 2014 г. $(0,00774)$, в 2017 г. $(0,00860)$ и в 2018 г. $(0,00748)$. Это означает, что в эти годы банковский сектор Молдовы обладал относительно процентного дохода большей финансовой устойчивости в рамках ценологической теории, чем в 2015 г. и 2016 г.

Таким образом, на примере банковского сектора экономики Республики Молдова с помощью процедур методики ценологического анализа экономических систем и разработанного показателя устойчивости осуществлены оценки его финансово-экономической устойчивости с 2014 г. по 2018 г. включительно. Значения этих оценок для каждого года позволяют осуществлять сравнительный анализ степени влияния мировых финансово-экономических кризисов и инвестиций, полученных от Международных Финансовых Организаций на устойчивость банковского сектора Республики Молдова. Анализ и сравнение конфигурации рангового параметрического распределения процентного дохода банков и его аппроксимирующей гиперболы Н-распределения дает возможность определить наиболее проблемные места банковского сектора, и на основании этого сформулировать рекомендации по реализации повышения его устойчивости.

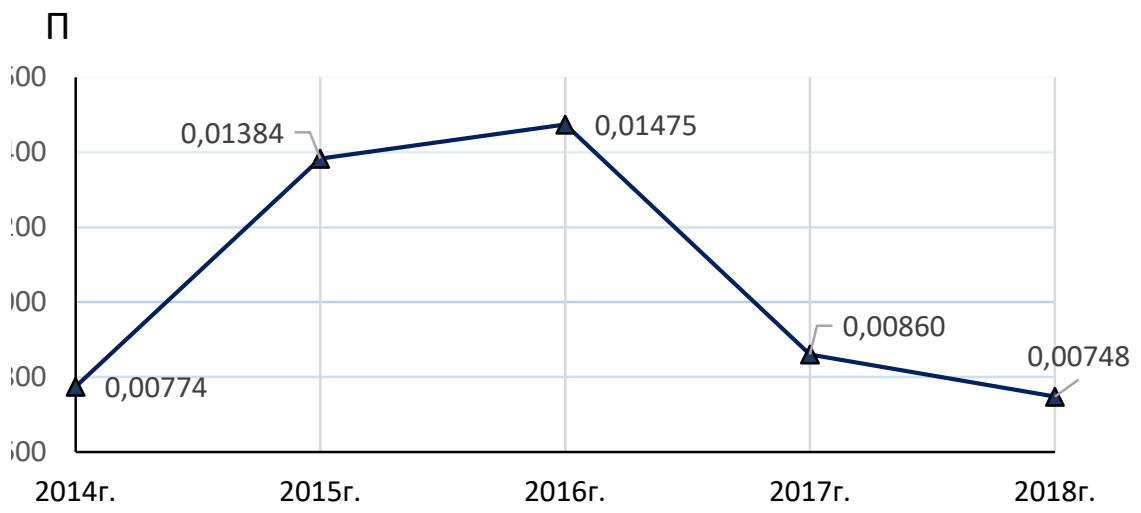

Рuc. 2. Показатель устойчивости (по отношению к процентному доходу) банковского сектора экономики Молдовы 


\section{Библиографический список}

1. Кудрин Б.И. Основы общей ценологии. Вып. 30. «Ценологические исследования». Томск: Изд-во Тгу Центр системных исследований, 2006.

2. Кудрин Б.И. Два открытия: явление инвариантности структуры техноценозов и закон информационного отбора / Под общ. ред Петровой Г.А. Вып. 44. «Ценологические исследования».- М.: Технетика, 2009.82 с.

3. Нельсон Ричард Р., Уинтер Сидней Дж. Эволюционная теория экономических изменений. - М.: Дело, 2002.

4. Ступачев С.А. Влияние международных финансовых организаций на страны с переходной экономикой // Финансовая экономика № 5(ч.7) С 864-865.

5. Фуфаев В.В. Экономические ценозы организаций.-М.-Абакан: Центр системных исследований, 2006. - 86 c.

6. Financial reports on the banking system. National Bank of Moldova. [Электронный ресурс].- Режим доступа.URL: https://www.bnm.md/bdi/pages/reports/drsb/DRSB6.xhtml (дата обращения 10.12.2019). 